\title{
LUCES Y SOMBRAS DE LA EUROPA SOCIAL*
}

\author{
Manuel María Zorrilla Ruiz \\ Catedrático de la Universidad de Deusto
}

\section{Promoción reciente del derecho a la Seguridad Social al rango de derecho fundamental en el ámbito comunitario europeo}

El elenco de los derechos fundamentales y libertades públicas -objeto de reconocimiento en la sec. $1 .^{\mathrm{a}}$, cap. $2 .^{\circ}$, tít. I CE- no ha dado entrada a los extremos que conciernen a la acción protectora del régimen público de Seguridad Social. Cierto que una lectura evolutiva del

* Texto actualizado de la intervención en la 25 Semana de Derecho del Trabajo, que, bajo el rótulo Futuro inmediato de Derecho Social, han organizado en Bilbao, el 4 y 5 de mayo de 1999, la Facultad de Derecho de la Universidad de Deusto y el Consejo General del Poder Judicial. Este trabajo — del que ha aparecido una versión en Actualidad Laboral, n. 37 (1999), págs. 703-719- se publica con la autorización correspondiente.

Las Sentencias del Tribunal Constitucional de 23 de noviembre y 15 de diciembre de 1983 establecen doctrina de base sobre el carácter indemnizatorio de las prestaciones sociales de carácter contributivo. La Sentencia del Tribunal Constitucional de 21 de mayo de 1987 resolvió el recurso de inconstitucionalidad que, impugnando un aspecto central y permanentemente polémico de la medida que se analiza en este estudio, interpusieron 54 diputados del Grupo Popular. Los Autos de la Sala 4. ${ }^{\mathrm{a}}$ del Tribunal Central de Trabajo de 9 y 28 de mayo de 1985 promovieron las cuestiones de inconstitucionalidad resueltas por la Sentencia del Tribunal Constitucional de 21 de julio de 1987. El Auto de la Sala de lo Social del Tribunal Superior de Justicia del País Vasco de 19 de noviembre de 1990 promovió la cuestión de inconstitucionalidad remanente que dio lugar a la Sentencia del Tribunal Constitucional de 8 de marzo de 1993.

En relación con el tema analizado, importa citar esta bibliografía: ALMANSA, «La llamada "concurrencia de pensiones" en la Seguridad Social», Revista de la Seguridad Social, n. ${ }^{\circ} 25$, pp. 61-76; AzNAR y otros, «La Ley de Pensiones desde la perspectiva constitucional», Revista Española de Derecho del Trabajo, n. ${ }^{\circ} 23$, pp. 321-369; CASAS, «Sobre la Ley de Presupuestos», Jurisprudencia sobre Trabajo y Seguridad Social, t. 5, Civitas, Madrid, 1988, pp. 115-143; MonTOYA, «Limitación de la cuantía de las pensiones en Ley de Presupuestos», Jurisprudencia sobre Trabajo y Seguridad Social, t. 5, Civitas, Madrid, 1988, pp. 264-276; SAN MARTín, «Seguridad Social y doctrina del Tribunal Constitucional; límites a las pensiones», Revista Española de Derecho del Trabajo, n. ${ }^{\circ}$ 68, pp. 991-1.009; 
art. 17.1 CE — según el cual, toda persona tiene derecho a la seguridad-permite, sin serios reparos constructivos y aun de acuerdo con el elemento de interpretación que conviene a las realidades sociales del tiempo y del lugar, entender el concepto jurídico — relativamente determinado- de seguridad con un alcance que, además de la salvaguarda de la seguridad individual, abarque y garantice los requerimientos de la Seguridad Social. De ahí, el derecho subjetivo de cada persona física a que, mediante técnicas de socialización racionalizadas y justas, los poderes públicos contraigan y cumplan el compromiso de compensar los perjuicios derivados de las situaciones de necesidad que más frecuentemente inciden en la normalidad de la existencia humana y la perturban, privando a los afectados de bienes jurídicos cuya pérdida origina un daño patrimonialmente resarcible. Así las cosas, el dato de que los arts. 41 y $50 \mathrm{CE}$ - respectivamente relativos al régimen público de Seguridad Social y a la cobertura de las situaciones de necesidad causadas por el abandono de la población activa- enuncien principios rectores de la política social y económica, no implica ninguna devaluación constitucional de una de las obligaciones preferentes del Estado social y democrático de Derecho que preconizan y destacan la dec. II Pr. CE y el art. 1.1. CE. Sólo refleja, en fe de la inquietud y el deber inherentes al propósito de transformación que proclama el art. 9.2 CE, la inaplazabilidad - todo lo contrario de una acción empañada por dilaciones o tibiezas - con que el legislador ordinario, al que el art. 53.3 $\mathrm{CE}$ dirige su mensaje, tiene que analizar la urgencia de los cambios previstos y desencadenarlos, completando — sin, por supuesto, desvirtuarla - la reflexión en pro de la naturaleza fundamental de ese derecho.

Semejante línea de pensamiento es manejable y persuasiva para configurar, usando de argumentos intrínsecamente constitucionales,

\footnotetext{
VALDÉS, «Sobre la constitucionalidad del establecimiento de topes máximos a las pensiones», Revista de Relaciones Laborales, n. ${ }^{\circ}$ 17, pp. 31-51.

Se utilizan las siguientes abreviaturas y siglas: APS, Acuerdo sobre Política Social adjunto al Prot. PS. art., artículo; C.c, Código Civil español de 24.7.(8)89; cap., capítulo; CCDSFT, Carta Comunitaria de Derechos Sociales Fundamentales de los Trabajadores de 8 y 9.12.89; CE, Constitución española de 27.12.78; CI, Constitución italiana de 27.12.47: Co., Convenio; cons., considerando; CSE, Carta Social Europea de 18.10.61; dec., decisión; LGSS, Ley General de la Seguridad Social de 20.6.94; LPGE.84, Ley de Presupuestos Generales del Estado para 1984, de 28.12.83; LPGE.99, Ley de Presupuestos Generales del Estado para 1999, de 30.12.98; mat., materia; OIT, Organización Internacional del Trabajo; Pr., Preámbulo; Prot. PS, Protocolo relativo a la Política Social, adicional a la VATUE; sec., sección; TA, Tratado de Amsterdam de 2.10.97; tít., título; VATR, Versión anterior del Tratado de Roma de 25.3.57; VATUE, Versión anterior del Tratado de la Unión Europea de 7.2.92; VCTR, Versión consolidada del Tratado de Roma, modificado por el TA; VCTUE, Versión consolidada del Tratado de la Unión Europea, modificado por el TA.
} 
como derecho fundamental el derecho a la acción protectora de la Seguridad Social. Ahora bien, otras razones poderosas se suman a las ya declaradas, para sostener, con base en las novedades que aportan, la más reciente fisonomía de un derecho que, según la tradición definidora de lo que los derechos fundamentales son y significan, pertenece a uno de los grupos integrantes de la sociedad pluralista que aspira, de presente, a su prosperidad colectiva y entiende que, sin su contribución, es inviable asegurar, en el futuro, la efectividad de su justa gobernación y su progreso.

El art. 136 I VCTR modifica el art. 117 I VATR, que — pese a la debilitación semántica de alguna que otra de sus versiones nacionales- reiteraba una cláusula transformadora y social cuya energía e intencionalidad no diferían de la inspiración de los arts. 3 II Cl y 9.2 CE. Conforme a las innovaciones que establece el art. 1.21 TA, dicha regla - estimulante de la necesidad, avalada por el común de los Estados miembros, de que la mejora de las condiciones de vida y de empleo fomente la igualación en el progreso de los trabajadores- se perfecciona con una declaración comprometida y ambiciosa. No se converge, al modo de coincidencia doctrinal o desde una perspectiva políticolegislativa, en la necesidad que así se realza, sino que se llega más lejos y - como corresponde a la intuición y la añoranza de una Europa social que pretende ser tal sin veladuras ni disfraces - se añaden dos proposiciones muy notables. La primera de ellas hace saber que la Comunidad y los Estados miembros - que, por el cauce del adelanto de sus soluciones, persiguen una equiparación eliminatoria de agravios o discriminaciones indeseables - tendrán como objetivo, entre otros que se especifican, el de una adecuada protección social. La otra recuerda que, a ese fin, la Comunidad y los Estados miembros emprenderán acciones que no pierdan de vista la diversidad de las prácticas nacionales. Precisión de suma importancia y que, a la hora de construir el correspondiente sector del ordenamiento jurídico europeo de la Seguridad Social, apunta sendas posibilidades. Cabe que las prácticas nacionales constituyan la base de las soluciones comunitarias o faciliten su adopción, porque de antemano se ajustan al espíritu y la finalidad del Derecho de gentes que se promete elaborar. También es dable que, al contrario, se juzguen prácticas impropias y corregibles, si — por estar ayunas de razonabilidad o derivar de arbitrismos injustificados- contradicen la universalidad de unos principios informadores que, según el art. 137.3 mat. 1 VCTR, forman parte del cuerpo normativo que, a propuesta de la Comisión y previas las adecuadas consultas, el Consejo debe edificar, por unanimidad, en lo atinente a la Seguridad Social de los trabajadores. 
Otra afirmación de hondo calado es la que, en el art. 136 I VCTR, profiere una calificación de espectacular importancia. El art. $2.58 \mathrm{TA}$ inicia la operación depuradora consistente en derogar el Prot. PS y el APS, que, sin pertenecer a la parte dispositiva de la VATUE, profería unas consignas de Política Social cuya sinceridad y brillantez decaían ante un enclave sistemático de muy costoso entendimiento. La consideración inicial del Prot. PS formulaba sólo el escueto deseo - algo menos que el designio programático y, en cualquier caso, lejano de la eficacia preceptiva directa- de aplicar, a partir del acervo comunitario o bloque de constitucionalidad europeo para cada materia, la CCDSFT, sin fortalecer el arraigo de los derechos y situaciones jurídicas allí contemplados, ni avanzar iniciativas desautorizadas por el carácter híbrido del texto de compromiso que las encarecía.

El art. 136 I VCTR - que asigna a la Comunidad y a los Estados miembro el objetivo de alcanzar una protección social adecuada- declara que, al conducirse así e ir en pos de esta finalidad, no pueden menos de tener presentes los derechos sociales fundamentales enunciados en la CSE y los que reconoce la CCDSFT, intencional e inequívocamente relativas a los derechos fundamentales de los trabajadores. $\mathrm{Pa}$ rece obligado concluir que, a la luz del discurso del constituyente comunitario, el derecho a la acción protectora de la Seguridad Social se consolida como un derecho fundamental y participa de los caracteres que adornan a esta categoría.

Cualquier observador crítico acepta la exigencia de que todos y cada uno de los ordenamientos jurídicos de los Estados miembro deben apropiarse y compartir las consecuencias de tan valioso reconocimiento. Hay que admitir que, a causa de ello, surgen obligaciones estatales de promover las reformas constitucionales que procedan y, en su caso, enmendar una distribución que ya no se condice con la naturaleza recién adjudicada a esos derechos. El art. 136 I VCTR cuida de proclamar - con el valor dogmático de su envío a unos textos anteriores que se revigorizan- que, además de los otros que va enumerando, el derecho a la seguridad Social de los trabajadores es un derecho fundamental. Dictado que, en un todo, se atiene a la naturaleza de las cosas, se impone a la voluntad del constituyente europeo - que, ante los horizontes constitutivamente históricos de la razón práctica, emite un juicio de esa repercusión y trascendencia- y, lejos de deberse a una actitud de otorgamiento complaciente, condiciona cualquier decisión normativa y es, por definición, inalienable e inseparable de la condición personal y profesional de los trabajadores a quienes favorece.

Puede cumplirse o pasarse por alto el imperativo del art. 136 I VCTR y, según ello, procederse o no a una reforma constitucional que, 
de acuerdo con la novedad que se sanciona, reconozca el derecho a la Seguridad Social y lo emplace bajo la rúbrica — que inicia la sec. 1. ${ }^{a}$, cap. $1^{\circ}{ }^{\circ}$, tít. I CE-De los derechos fundamentales y de las libertades públicas. El que se omita esta labor de adaptación y no se use del procedimiento de reforma que establecen los arts. 87.1 y 2 , y $168.1 \mathrm{CE}$, no quiere decir, ni mucho menos, que la rotunda propuesta que se aporta - al situar la Seguridad Social en el campo de los derechos fundamentales- deje de producir las rigurosas consecuencias tecnicojurídicas de la calificación que se imparte.

He aquí uno de los aspectos en que opera el principio de primacía del Derecho Comunitario. Su formulación general enseña que, como especie del principio de jerarquía normativa, las reglas jurídicas - cualquiera que sea su rango- emanadas de los órganos comunitarios competentes para producirlas, prevalecen sobre las que — destinadas por los ordenamientos jurídicos de los Estados miembros a regular instituciones o materias homólogas- contradicen las normas superiores del Derecho fundamental o derivado. Ahora bien, la primacía es algo más que la preponderancia excluyente o el prevalecimiento del mandato o la prohibición de una norma jurídica europea sobre una disposición estatal que, ante la incompatibilidad que surge entre ambas, debe inaplicarse al menos, si no hay dispositivos - más enérgicos- que permiten expulsar del ordenamiento jurídico la norma de rango inferior que causa la contradicción. La primacía no atañe únicamente a la relación jerárquica que interviene y debe observarse en la disciplina de una institución determinada, sino que afecta también a la naturaleza que le es propia y a la calificación axiológica que de ella se predica. El Derecho de cualquiera de los Estados miembros no puede, so pena de violar el principio indicado, disminuir la dignidad ni degradar la naturaleza jurídica de una institución que las normas comunitarias configuran más esmeradamente, o a la que asignan una condición superior o procuran una tutela más intensa que la que, en paralelo, le otorga la legalidad constitucional u ordinaria del Estado.

El principio de primacía del Derecho Comunitario exige que, en vista de una contradicción de ese calibre, el Estado miembro - cuya legislación debe enmendarse para corregir semejante anomalía - reforme la legalidad constitucional y/o ordinaria en la medida requerida por la necesaria adecuación. A falta de estas operaciones, es absolutamente indispensable que la calificación otorgada por el ordenamiento jurídico comunitario a la institución de que se trata — mejorando, por definición, la que propician uno o varios de los Estados miembros- se imponga a todas y cada una de las instancias de los mismos, que quedan vinculados por el tratamiento que introduce el Derecho fundamental o 
derivado. La naturaleza fisonómica que el Derecho comunitario asigna a determinada figura o la intensidad con que vela por los intereses que incorpora, no puede verse contradicha ni desautorizada por los criterios - divergentes o neutralizadores - que el Derecho constituido de uno o varios de los Estados miembros mantiene en punto a su régimen jurídico.

A esta reflexión ayudan la cláusula general de desarrollo del art. 41 $\mathrm{CE}$ - relativo, entre otros pormenores, a la suficiencia de las prestaciones sociales - y la significativa exigencia, que el constituyente no hace suya por motivaciones estéticas o gratuitas, de que las prestaciones de jubilación y/o retiro sean, como reza el art. $50 \mathrm{CE}$, adecuadas y objeto de actualizaciones periódicas. Tales principios - elevados por el art. 136 I VCTR a la categoría de derechos fundamentales de sus beneficiarios- no toleran desarrollos legislativos nacionales que, al albedrío de los Estados miembros, den cabida a soluciones en pugna con las pautas del que, según la reserva del art. 137.3 mat. 1 VCTR, está llamado a ser el Derecho común europeo de la Seguridad Social y a dotar de las reglas — generales y superiores- que esos legisladores deben acatar y de las cuales no pueden disentir.

El haz de derechos subjetivos que abarca la acción protectora de la Seguridad Social, deja de ser la proyección legislativa de un principio rector de la política social y económica y pasa a desarrollar la categoría de derechos fundamentales que data de la remisión - hecha en el art. 136 I VCTR - a los textos garantizadores de unos derechos sociales en los que la CSE y la CCDSFT alojan el concepto de Seguridad Social. Es - hay que reiterarlo- jurídicamente inadmisible que el ordenamiento jurídico de cualquiera de los Estados miembro mantenga al respecto diferencias de trato que - como la consistente en rebajar esos derechos al nivel programático que, en principio, les asignó el art. 53.3 $\mathrm{CE}$ - carezcan de justificación objetiva y razonable, pues ello supone deparar a los beneficiarios del régimen público de la Seguridad Social una protección discrepante de la excelencia que el constituyente comunitario acaba de reconocerles.

No en vano - hay que advertirlo así- la alusión a las prácticas nacionales de los Estados miembros encierra una prevención que, entre otras hipótesis, encara la de que, por conveniencias arbitristas o condicionamientos económicos, el decisionismo legislativo de alguno de aquéllos no esté de acuerdo ni a la altura de la óptima calificación de los derechos subjetivos a los beneficios de la Seguridad Social. Esas prácticas nacionales - que, en más de una ocasión, se han ganado la merecida reputación de recusables - tienen que acomodarse a la ordenación uniforme - superadora de la vieja técnica de coordinación de 
las políticas sociales nacionales- que, como ordena el art. 137.3 mat. 1 VCTR, debe emprender el Consejo a propuesta de la Comisión. $\mathrm{Al}$ primero incumbe el cometido de formular e imponer los principios informadores - comunes y obligatorios - que las legislaciones nacionales no han uniformado, porque no estaban obligadas a hacerlo de inmediato, ni han acertado a coordinar en la medida necesaria para reducir los agravios diferenciales y eliminar las soluciones arbitristas que escapan a cualquier tentativa de control eficaz.

\section{Insuficiencia e inadecuación de los límites que las sucesivas Le- yes de Presupuestos Generales del Estado han impuesto al creci- miento y concurrencia de las pensiones públicas contributivas de jubilación y/o retiro}

Desde la entrada en vigor de la LPGE.84 y durante los consecutivos periodos anuales, la ordenación de los Presupuestos Generales del Estado ha insertado, sistemática e indefectiblemente, una cláusula que afecta como sigue al régimen de las pensiones públicas contributivas de jubilación y/o retiro:

1) Cualquiera que sea el importe de una de dichas prestaciones, concedida merced al cumplimiento de las condiciones legalmente previstas para reconocerla y liquidada de acuerdo con las reglas que determinan su cuantía, no puede exceder de la cifra que, fijada en cada una de las anualidades sucesivas, asciende hoy a un total de 295.389 pesetas mensuales.

2) Cuando un mismo beneficiario reúne los requisitos necesarios para que se le reconozcan sendos derechos subjetivos a percibir dos o más pensiones públicas compatibles, ambas le son atribuidas, pero, cualquiera que sea la suma de los respectivos importes, no puede obtener, por ambos conceptos, una cantidad superior a ese límite.

3) Cuando una sola de las prestaciones compatibles no es inferior a dicho techo, el acreedor sólo tiene derecho a percibir el importe de la tasa fijada y, no obstante habérsele reconocido el derecho a lucrar otra pensión concurrente, queda privado de su pago.

Llevada la reflexión al campo de la suerte que, a causa de la restricción cuestionada, corren las pensiones públicas contributivas de jubilación y/o retiro, su crítica - evocadora de los argumentos manejados al plantear las pertinentes cuestiones de inconstitucionalidad- debe fun- 
darse en los arts. 41 y $50 \mathrm{CE}$, cuyas condiciones de suficiencia y adecuación de dichos beneficios se analizan para situar el problema en el plano de la seguridad jurídica, que debe gobernar ese régimen, y sustraer sus peripecias al de las ligerezas arbitristas o compromisos que le entenebrecen. Los arts. 136 y sigs. VCTR dotan de una perspectiva que destaca, por encima de todo, a la hora de rehacer el discurso sobre la materia.

Las cualidades o notas de suficiencia y adecuación - que han servido para nominar, con distintos términos, el mismo concepto- de las pensiones públicas contributivas de jubilación y/o retiro, compensatorias del abandono de la población activa, no pueden trivializarse como el maleable objeto de interpretaciones libérrimamente alternativas o de opciones que usan de la definición más conveniente para satisfacer preferencias que, so pena de depredar los valores de la naturaleza de las cosas, no justifican las deformaciones aberrantes ni las suplantaciones conceptuales. Esos beneficios sociales dimanan de la constancia de situaciones de necesidad individuales y sólo enjugan — por exigirlo así la limitación de los recursos disponibles - una parte del daño causado por la contingencia consistente en la salida de la población activa a que se pertenece hasta entonces. La acción protectora oficial, previa a la adquisición y el goce de dichas prestaciones, no pretende conseguir la reparación íntegra del desmerecimiento que -implícito en la situación de necesidad tutelada y conforme a la regla central del Derecho común de la responsabilidad que profiere el art. 1.106 C.c. - se compone del daño emergente o pérdida sufrida y el lucro cesante o ganancia dejada de obtener. La idea de integridad satisfactoria de las prestaciones - consecuente con el principio de responsabilidad patrimonial universal que, según el art. 1.911 C.c., regula el cumplimiento de las obligaciones de Derecho común- difiere de las nociones de suficiencia y adecuación que los arts. 41 y 50 CE no utilizan demagógica ni retóricamente. La integridad de la reparación presupone el resarcimiento exhaustivo y cabal del daño que debe compensarse. La suficiencia y adecuación significan, en cambio, que la prestación social ha de alcanzar una cuantía razonablemente próxima a tal integridad, y que en modo alguno puede resultar desproporcionada y espectacularmente inferior a la magnitud a la que sustituye. Las nociones de suficiencia y adecuación han de entenderse unívocamente y se oponen a la tentativa de convertirlas en conceptos equívocos que desfiguran y pervierten la finalidad universal de protección que aquellas prestaciones persiguen en un régimen público de Seguridad Social. La legalidad fundamental admite - en ciertos puntos que el pluralismo político respalda - lecturas cambiantes y elásticas del pensamiento originalista del constituyen- 
te, pero, en los aspectos caracterizados de antiguo por lo inconmovible y recio de su comprensión tecnicojurídica, no autoriza interpretaciones veleidosas.

Cuando los arts. 41 y $50 \mathrm{CE}$ prescriben la suficiencia y adecuación de las pensiones públicas contributivas de jubilación y/o retiro, están lamentando, entre líneas, que las correspondientes prestaciones no lleguen a ser íntegras y que no cubran por completo la pérdida de la utilidad económica que, tras haber cesado en sus actividades, deja de obtener su perceptor. Suficiencia y adecuación no significan nociones mudadizas que, en un tema tan serio, el constituyente ha puesto en negro sobre blanco para desafiar, sin más, a la imaginación o volubilidad de los intérpretes, sino que están ahí para reclamar y merecer un riguroso entendimiento. Lo demanda la impronta de una tradición y de unos objetivos que, a causa de su elaboración pausada y reflexiva, deben preservarse escrupulosamente en lo que son y significan. Una pensión pública contributiva de jubilación y/o retiro es adecuada si, en términos comunes, su importe se acerca equitativamente al del resarcimiento del perjuicio engendrado por la situación de necesidad correspondiente. La adecuación falta si se aleja aparatosamente de dicha cuantía y deja en pie los efectos negativos del daño que se pretende indemnizar. Una pensión pública contributiva de jubilación y/o retiro es suficiente si, atendido su importe, provee a las mismas o aproximadas exigencias que, antes de ocurrir la contingencia, se atendían con los emolumentos que deja de percibir el pensionista. Suficiencia y adecuación son términos procedentes de un acervo cultural que - a causa de la intencionalidad con que el constituyente da entrada a su significación y entendimiento- rechaza las versiones de los nacionalismos discrepantes $o$ morosos que las deforman y hacen irreconocibles. Los arts. 41 y $50 \mathrm{CE}$ se comprenden -máxime cuando el art. 136 I VCTR hace suyo un derecho fundamental a la Seguridad Social que, según el art. 10.2 CE, debe interpretarse conforme a las normas del Derecho de los pueblosen clave de estas reflexiones y al margen de cualquier tentación que no comulgue con su preciso alcance. Los conceptos de suficiencia y adecuación de las pensiones públicas que se analizan, se resienten de una interpretación arbitraria - prohibida en el art. 9.3 CE-cuantas veces se apartan de la inequívoca orientación que suministra el art. 65.1 Co.102 OIT.

La formación de la relación protectora que hace nacer el derecho subjetivo a percibir una pensión pública contributiva de jubilación y/o retiro, depende del concurso de los requisitos — a saber, adscripción formal al régimen público de Seguridad Social, observancia del periodo de espera y cumplimiento de una determinada edad- que señala el 
legislador ordinario. Reunidas las cuales, la cuantía de la prestación se calcula mediante reglas que, para garantizar la suficiencia y adecuación de que se trata, se incorporan a fórmulas aritméticas que computan los haberes devengados durante la vida profesional y cuyas operaciones determinan unos resultados numéricos que se aproximan a los emolumentos activos. Es la equivalencia o cercanía razonable a la compensación íntegra del perjuicio sufrido, la que atribuye la cualidad de suficientes y adecuadas a las prestaciones sociales cuyo importe se liquida según tales criterios de cálculo.

La correlación existente entre la cifra de las cotizaciones efectuadas al régimen público - cuyas bases han sido los emolumentos determinantes del sacrificio impositivo y, en definitiva, de la cuantía de las cuotas-y las pensiones públicas contributivas de jubilación y/o retiro, no constituye un simple expediente numérico para facilitar la liquidación de estas últimas, sino una consecuencia indeclinable de las características de adecuación y suficiencia que en ellas deben concurrir. La solución que parte de las bases de cotización efectivas - directamente conexas con la cifra de sueldos o salarios que con las mismas coinciden- se obtiene a partir de una verificación técnica y no de un artificio marginal o accesorio, al que, sin otras razones de peso, se acude con el único fin de aligerar las operaciones de cálculo. La justificación de esas fórmulas reside en su aptitud para garantizar un resultado que, evitando un grueso perjuicio a los intereses del beneficiario, asegura una renta pasiva equivalente o muy cercana a la que exige la atención de la situación de necesidad protegida. Dicha correlación cuantitativa se predica tanto de las relaciones protectoras del régimen público de Seguridad Social, como de las típicas del aseguramiento privado, aunque difieren los respectivos títulos de procedencia. Éstas implantan la correlación por obra de la autonomía contractual que soberanamente fija la extensión económica de los beneficios pactados. Aquéllas requieren que toda prestación pública que se precie de suficiente y adecuada, procure una utilidad no distinta de la que, al sobrevenir la contingencia de retiro, dispensaban las retribuciones tenidas en cuenta para liquidar unas cotizaciones dependientes de la capacidad de sacrificio contributivo del sujeto.

La suficiencia y adecuación de las pensiones públicas contributivas de jubilación y/o retiro pertenecen al contenido esencial o núcleo invulnerable de los derechos subjetivos a la Seguridad Social que - relegados al papel programático de los principios rectores de la política social y económica en el cap. $3 .^{\circ}$, tít. I CE - se consolidan — esta vez, en la esfera del ordenamiento jurídico comunitario-como nuevos derechos fundamentales cuyo reconocimiento, a cargo del cons. 4 Pr. 
VCTUE y el art. 136 I VCTR, renueva los supuestos del problema que así se suscita.

La suficiencia y adecuación de las pensiones públicas contributivas de jubilación y/o retiro quiebran tan pronto como las operaciones aritméticas - llevaderas al cálculo de una cifra de prestación equitativa y no confiscatoria-arrojan resultados que, al exceder de los límites fijados en las normas elaboradas por el procedimiento que regula el art. 134.3 a 5 CE, se reducen a las cantidades que, de 1984 a 1999 , han oscilado entre 187.950 y 295.389 pesetas mensuales. Se trata de un techo que, cuantas veces rebaja aparatosamente la cuantía originaria que proviene de aplicar la fórmula prevista al efecto, se aleja sin razón de la cantidad bastante para resarcir - ya que no totalmente, sí que de modo suficiente y adecuado- el daño anejo a la contingencia causante de la situación de necesidad. Las pensiones públicas contributivas de jubilación y/o retiro que, condicionadas por la tasa de crecimiento y concurrencia, acusan una lesión considerable y notoria del interés legítimo de sus perceptores, quedan destituidas de las notas de suficiencia y adecuación que, según los arts. 41 y $50 \mathrm{CE}$, deben asistirles.

\section{Insuficiencias tecnicojurídicas de la regulación que se analiza}

Cae de su peso que a la noción y efectos de un derecho legítimamente adquirido y asignado repugna el albedrío legislativo que, al objeto de reducir el gasto público incidente sobre las partidas sociales, elimina el interés peculiar de su titularidad y ejercicio. Todo interés legítimo - protegido por el ordenamiento jurídico para su conversión en derecho subjetivo - cuenta con la efectiva tutela judicial que, según el art. 24.1 CE, garantiza la posibilidad y utilidad de su realización, de suerte que el legislador — cuya arbitrariedad está proscrita en el art. 9.3 $\mathrm{CE}$ - no puede privar del mismo al sujeto que lo ha ingresado en su patrimonio conforme a Derecho. El legislador no es dueño de deformar a voluntad la estructura de un derecho subjetivo inviolable, ni de despojarle por completo de la utilidad económica propia del interés que ha sido objeto de una reflexiva protección. Así lo impone la naturaleza de las cosas que es, en definitiva, una expresión del valor superior de la justicia y de los imperativos de la lógica que manda respetar el art. 1.1 CE. Ello, en el caso - más que discutible- de darse por bueno que, aún cuando soberanas, esas iniciativas del legislador no tienen la condición de expropiatorias ni producen la confiscación de derechos que prohibe el art. $33.3 \mathrm{CE}$. 
Una ley caracterizada por lo discutible de sus garantías como norma jurídica general, arrebata su utilidad a un derecho subjetivo reconocido por un acto de la Administración Pública que ha aplicado irreprochablemente las reglas relativas a las condiciones necesarias para su adquisición. Situación a que aboca la norma - reiteración indefectible y sistemática de sus antecesoras- con que el art. 40.2 LPGE. 99 establece que el acreedor de una pensión pública contributiva de jubilación y/o retiro - regularmente atribuida por el órgano competente para concederla - no puede ejercitar el derecho subjetivo que le corresponde ni beneficiarse de su interés económico, si ya goza de otra prestación que - concurriendo válidamente con ella y no estando afectada de incompatibilidad - asciende a una cuantía que rebasa el expresado límite. El alegato de haberse vulnerado la seguridad jurídica — que el art. 9.3 CE cuida de garantizar - no es un argumento de adorno o acumulación, sino un clamor de rebeldía en pro de una exigencia que el Estado social y democrático de Derecho ordena respetar .

Las siguientes proposiciones sintetizan el resultado de lo precisado hasta el momento:

1) Se atenta contra las exigencias — naturales e irrenunciables - de suficiencia y adecuación de las pensiones públicas contributivas de jubilación y/o retiro, si su cuantía se reduce a un máximo que, lesiva y aparatosamente, es inferior al resultado de aplicar la fórmula originariamente dirigida a procurar una cantidad aproximada o sustitutiva de las percepciones que dejan de obtenerse.

2) Igual vulneración existe cuando, absoluta e incondicionadamente, se priva al beneficiario del goce de una prestación cuya titularidad se le ha adjudicado conforme a los requisitos que instituye el ordenamiento jurídico.

3) La suficiencia y adecuación de esas prestaciones constituye una exigencia innata que pertenece al contenido esencial o núcleo invulnerable de derechos fundamentales reconocidos por el constituyente europeo y que los Estados miembros no pueden eludir ni desvirtuar a su albedrío.

4) Dichas características se predican del Derecho de gentes europeo, llamado a fijar, en el ámbito de la Seguridad Social, los principios inconmovibles que - sin posibilidad de contradicción o disidencia por parte de los legisladores nacionales - regulan la posición de los sujetos de las relaciones protectoras de jubilación y/o retiro, fijan las condiciones de suficiencia y adecuación a su objeto, y ordenan los pormenores concernientes a su constitución, modificación y extinción. 


\section{Aspectos que, desde la perspectiva constitucional, concurren en el examen originario del problema}

El planteamiento de las cuestiones y recursos de inconstitucionalidad promovidos para denunciar ese vicio, provocó una respuesta desestimatoria de las pretensiones que a la sazón se ejercitaron. Sorprende, entre otros aspectos criticables, la singularidad del criterio -inédito hasta entonces- de que se echó mano para definir la suficiencia de las prestaciones de jubilación e identificar su concepto con el de la escueta superación de los linderos que señalan los umbrales de la marginación y la pobreza. Consideración que, al margen de las circunstancias de coyuntura que aconsejaban semejante medida, desatendía las aspiraciones inherentes al progreso de la Seguridad Social y se confabulaba con ideas regresivas y en modo alguno merecedoras de elogio.

Dicha postura prescinde del elemento de interpretación contextual que, según el art. 10.2 CE, obliga a construir la noción de suficiencia de acuerdo con las normas supranacionales contenidas en los instrumentos ratificados por España. Reparo que, hoy día, se refuerza con la atribución del carácter de derechos fundamentales que el constituyente europeo confiere a los derechos subjetivos a la Seguridad Social. El art. 65.1 Co.102 OIT - cuyo imperativo debió sobreponerse a la interpretación nacionalista de la suficiencia e impedir su censurable innovación- encierra una norma mínima o de orden público que ningún legislador de los Estados miembros puede defraudar con soluciones que, como la denunciada, reposan en objeciones de naturaleza económica. Dispone aquel precepto que el cálculo de los pagos o prestaciones periódicas debe efectuarse sobre el todo de las ganancias anteriores de los beneficiarios, cuyos importes se tienen en cuenta para cuantificar el sacrificio contributivo de quienes han visto minoradas sus remuneraciones en las cifras de las cotizaciones abonadas a lo largo de su vida profesional. Hay que advertir, a mayor abundamiento, que —antes de patrocinar la idea de la suficiencia cuasibenéfica de las prestaciones sociales - la justicia constitucional había discurrido impecablemente sobre el particular y aceptado que, conforme a la mejor doctrina, la normativa legal de la acción protectora del sistema de la Seguridad Social no se basaba en la idea de tutela y sí en la del resarcimiento o compensación del daño causado al perceptor de las prestaciones sociales que sustituían a las remuneraciones o rentas dejadas de obtener.

La orientación trazada por la justicia constitucional, al resolver los problemas de inconstitucionalidad que había abordado, provocó las reacciones consecuentes con la inconsistencia de los argumentos manejados para sostener que el límite estrenado en el art. 51.1 y 4 LPGE.84 no in- 
fringía ningún principio ni precepto de la legalidad fundamental. $\mathrm{Su}$ restricción -ininterrumpidamente reiterada, a partir de entonces, en los textos anuales de esta naturaleza e irregularmente trasladada al art. 47 LGSS - se ha mantenido hasta su actual reproducción en el art. 40.1 y 2 LPGE.99. Ocurre así, porque se trata de normas cuya vigencia -estrictamente anual_- urge a una repetición que holgaría en el caso de corresponderles la naturaleza permanente y la duración ilimitada de que carecen por definición. El poder de convicción de los reproches que ha merecido esta medida, prima — dadas la densidad y reflexión de su discurso - sobre los argumentos dirigidos de adverso a neutralizar las objeciones de constitucionalidad que se adujeron.

Yerra, ante todo, la teoría - más voluntarista que intelectualizadade que los futuros beneficiarios de las pensiones públicas contributivas de jubilación y/o retiro no son titulares de un derecho subjetivo a que dicho beneficio económico se les reconozca por el importe resultante de computar, a efectos de su cálculo y liquidación, las cuotas que el trabajador satisfizo en el curso de su vida activa. La idea - defendida con ese designio- de que la correlación entre las cifras de las bases de cotización y la cuantía de las prestaciones periódicas es propia de las relaciones de aseguramiento privado, no quiere decir, ni mucho menos, que la conexión no se predique, aunque sea por distinto título, del supuesto de la protección social que se analiza. Aun sin tratarse de un estado de cosas generado por la autonomía de la voluntad particular, la obligatoriedad de esa aproximación cuantitativa es consecuencia ineludible e implacable de la nota de suficiencia objetiva que debe acompañar a las prestaciones sociales económicas, y que, como se infiere del art. 65.1 Co. 102 OIT, presupone un concepto inequívoco que disipa las dudas sobre cualquier otra versión alternativa.

No es menos inaceptable la propuesta de que la minoración cuantitativa - frecuente causa de una lesión enorme para la economía individual y familiar de los perceptores de las prestaciones degradadas- no da lugar a privación alguna de derechos. Este discurso - cuya superficialidad se trae a capítulo para salir del paso- ignora que la integridad de la estructura de un derecho subjetivo no se reduce a la adjudicación $e$ individualización de su titularidad, sino que, conforme a la doctrina pacífica que de antiguo atañe a la vestidura de los intereses legítimos y acreedores a la protección del Derecho, abarca también lo concerniente a la cumplida atención de ese interés, como algo inseparable de la apetencia que le es consustancial y de la utilidad que, esperada del mismo, debe procurar. Una disminución sensible del objeto económico de las pensiones públicas contributivas de jubilación y/o retiro - como la que ahora figura en el art. 40.1 y 2 LPGE.99- inutiliza el cumpli- 
miento de la función social reconocida por un ordenamiento jurídico que, en ese punto, pretende aligerar las cargas peculiares de un periodo especialmente delicado de la vida individual y social. La tesis criticada da de lado a un elemento inseparable del contenido esencial o núcleo invulnerable de un derecho que sufre el quebranto de su integridad objetiva, a falta de la cual, como reza el art. 1.157 C.c., no se entiende pagada la deuda correspondiente a la cuantía de una obligación caracterizada por los rasgos de suficiencia y adecuación que se conculcan.

Los derechos sociales - de que forman parte las pensiones públicas contributivas de jubilación y/o retiro- han dejado de pertenecer al programa, más o menos posibilista y diferido, de una sociedad que los reconocía conforme a criterios dependientes de las circunstancias económicas que marcaban el ritmo de su proceso de transformación. Los más recientes compromisos de la Europa social desvanecen las dudas sobre el giro copernicano que registra ese estado de cosas. La pausada y descomprometida perspectiva de antaño cede ante la noticia y la conciencia de que algo tiene que cambiar de raíz en la política de la Seguridad Social de los Estados miembros y que los arbitrismos nacionalistas — de que la edificación y desarrollo de la misma se han resentido tantas veces- tienen sus días contados. El acceso a los beneficios sociales se reviste de la nota de inviolabilidad que el art. 10.1 CE predica de los derechos que, en cuanto naturales o básicos, son indisociables de la dignidad de la persona humana - a la que corresponden por el hecho de su mera existencia- y reflejan su cosmoeminencia o superioridad sobre el resto de los seres - animados o no- que pueblan el mundo y están a su servicio. Dependencia de la que no se eximen los valores e intereses de la economía que se invocan para ungir sacramentalmente la medida restrictiva de que se discrepa. Es central advertir que, por encima de las predisposiciones domésticas de orden nacional, el cons. 4 Pr. VCTUE y el art. 136 I y II VCTR asignan, por modo de reconocimiento inaplazable y no de voluntarismo contingente, a los derechos sociales de los trabajadores públicos y privados — sin exceptuar el derecho a la Seguridad Social-la naturaleza y condición de derechos fundamentales. El detrimento criticado es aún más reprochable, si se llega al extremo de que - por concurrir con otra pensión pública, legítimamente atribuida y cuya cifra no es inferior a la tasa fijada en la legislación presupuestaria - el beneficio de la prestación se agota en el reconocimiento de la nuda titularidad del derecho y no genera percepción alguna, aun cuando el acreedor haya cumplido las condiciones requeridas para obtener el disfrute de que se le priva.

El uso inteligente de la lógica destruye la tesis — sostenida en pro de la limitación que se censura- de que las reducciones sufridas por 
las pensiones públicas de jubilación y/o retiro no atentan contra los rasgos de suficiencia y adecuación que predicen los arts. 41 y $50 \mathrm{CE}$. La globalidad del sistema protector es el argumento empleado para sostener que el desmerecimiento económico de ciertas relaciones de protección social - caso de las prestaciones reducidas a un límite máximo o rehusadas por exceder del mismo el importe de una de las que son entre sí compatibles - no entraña, por sí solo, semejante defecto, pues, desde un punto de vista totalizador, el perjuicio que sufre el conjunto de dichos pensionistas se compensa con las ventajas adquiridas por otros grupos de destinatarios de los beneficios sociales. El razonamiento empleado ignora que, siempre a la luz del bloque de garantías del art. 9.3 CE, ni siquiera el legislador ordinario tiene un poder de vida y muerte sobre los derechos subjetivos, sino que sólo es el agente razonable y solícito de su reconocimiento y regulación, conforme a una voluntad del legislador constituyente que no puede tolerar un desarrollo arbitrario, ni desautorizar principios de aceptación indiscutida en un círculo determinado de cultura. No cabe reaccionar así ante situaciones que hoy exigen un ejercicio de la función legislativa consecuente con la naturaleza actual de los derechos sociales y con el realce que, como reflejo de los nuevos derechos fundamentales, adquieren los caracteres de suficiencia y adecuación de las pensiones públicas contributivas de jubilación y/o retiro. Todo derecho subjetivo -incluidos los derechos innatos de corte social que el art. 136 I y II VCTR acaba de canonizar- se identifica, como conviene a su contenido esencial o núcleo invulnerable, con relación a un titular individual — persona física o jurídica - que inicialmente ostenta un interés legítimo y que, andando el tiempo, satisface su anhelo de lograr la tutela jurídica de las ventajas económicas que trae consigo su disfrute. El legislador no puede transformar, a su albedrío, el régimen de atribución constitutiva de derechos individuales — de que es ejemplo el de la asignación de las pensiones públicas contributivas de jubilación y/o retiro- en una titularidad en mano común que, como resultado de una construcción doctrinal de solidez mínima, carece de base tecnicojurídica y de precedente alguno que la justifique. Debe quedar claro que los derechos sociales de los correspondientes titulares - que los adquieren gracias al cumplimiento de las condiciones establecidas por la ley- tienen la condición de derechos de cada particular, cuyo patrimonio acrecientan, y de derechos colectivos, en cuanto que corresponden a la esfera jurídica de individuos predeterminados por su pertenencia a un grupo social específico, pero nunca adquieren el carácter de derechos subjetivos de los que - difusa e imprecisamente - sea titular la propia colectividad en que esas personas físicas están integradas. 


\section{Ausencia de fundamento estructural que sustente la fijación de los límites impuestos por las Leyes de Presupuestos Generales del Estado}

El art. 47 LGSS refrenda gratuitamente el criterio de que, por necesidad de precepto, la Ley de Presupuestos Generales del Estado ha de fijar un límite al crecimiento y concurrencia de las pensiones públicas contributivas de jubilación y/o retiro. Dos objeciones se oponen a la validez y aplicación de esta regla. Una, la de que el art. 47 LGSS forma parte de un cuerpo de legislación delegada en la modalidad del texto refundido que, según el art. 82.1 y $5 \mathrm{CE}$, requiere la preexistencia de las normas que se agrupan y reordenan sistemáticamente, lo cual prohíbe dar cabida en la refundición a preceptos de nueva factura. Así se infiere de lo que los dogmas de legalidad y seguridad jurídica cuidan de garantizar en el art. 9.3 CE. La novísima letra del art. 47 LGSS no pertenecía a ningún pasaje cronológicamente anterior al texto que lo incluye y se presenta como el ingrediente y feliz resultado de una refundición en la que, contra la naturaleza de esta variante normativa, hace acto de presencia por primera vez. ¿Qué valor se le otorga en vista de tal anomalía? Amén de este defecto que le inutiliza jurídicamente, el art. 47 LGSS prejuzga que - lejos de constituir un límite eventual y condicionado a las circunstancias que pueden autorizar o exigir su supresión- la tasa de crecimiento y concurrencia de las pensiones públicas contributivas de jubilación y/o retiro es un elemento inconmovible de la estructura de las relaciones protectoras de Seguridad Social, cuando, en propiedad, conculca varios de los principios universales e inalterables del Derecho rector de la materia.

La deformación consumada al amparo del art. 47 LGSS ha permitido - con toda la gravedad que la medida implica - sustraer definitivamente al Parlamento, que no ha vuelto a reivindicar tal competencia, el debate de un aspecto de la política económica cuyo análisis y decisión debieron producirse en dicha sede y no acudiendo a la ventaja del art. 134.3 a 5 CE, utilizado, hasta el momento, para preterir el contenido esencial o núcleo invulnerable de derechos sociales que hoy ascienden al rango de derechos fundamentales y que, en su calidad de inalienables, no soportan tamaña erosión.

De ahí, lo jurídicamente censurable de fundar el establecimiento de esos límites en motivaciones económicas que, sin ser condición básica y permanente del régimen de disfrute de los beneficios sociales, sólo pueden traerse a capítulo y operar como criterios de coyuntura - todo lo contrario de la indefectibilidad que les asigna el art. 47 LGSS-y deben cesar tan pronto como desaparezcan o decaigan las circunstan- 
cias de excepción que las originaron. Las reglas universales -provenientes de una construcción tecnicojurídica que generaliza las fórmulas de cálculo de las prestaciones sociales- del Derecho Público de la Seguridad Social, acerca de la titularidad de los derechos subjetivos correspondientes y la determinación de su extensión económica, son indisociables del dogma de suficiencia y adecuación de las pensiones públicas contributivas de jubilación y/o retiro. Conviene añadir que los llamados principios rectores de la política social y económica (cap. 3. ${ }^{\circ}$, tít. I CE) no incluyen estos dos últimos adjetivos de su rotulación por simples conveniencias estéticas o testimoniales. Dan a entender que, si los arts. 41 y 50 CE sientan unas proclamaciones trascendentes en tema de política social, ello es así, porque la política económica-que posibilita el logro de sus objetivos - nunca puede apelar a soluciones intelectualmente débiles o recursos arbitristas que frustren la garantía ofrecida por el constituyente. Idea que se revigoriza al advertir que las que, según su etiqueta de origen, fueron orientaciones programáticas de cuyo reconocimiento, respeto y protección se ocupaba el art. 53.3 $\mathrm{CE}$, se han visto elevadas a la categoría de derechos fundamentales europeos y dotadas de una condición que, en virtud del principio de primacía del Derecho comunitario, mejora su primitiva naturaleza constitucional y, cuando menos, les transfiere el tratamiento propio de los derechos fundamentales y libertades públicas que figuran en la sec. 1. ${ }^{\mathrm{a}}$, cap. . $^{\circ}$, tít. I CE.

La noción de indispensable solidaridad colectiva - evocada, de paso, en el art. 42.1 CE y diferente del principio de solidaridad interautonómico que proclaman los arts. 2 y $138.1 \mathrm{CE}$ - no puede intervenir, al uso de un principio demoledor de cualesquiera situaciones jurídicas que el Derecho objetivo reconoce, si no preexiste un precepto concreto - cuya figura rectora o supuesto de hecho incorpora el valor de la solidaridad y tipifica alguna de sus aspiraciones - o no media una circunstancia tan relevante y apreciable - lo contrario de generalizada y difusa - que determina inexorablemente que el respeto al derecho de los demás — exigido en el art. 10.1 CE — consista nada menos que en la pérdida o el sacrificio de un derecho propio. La invocación platónica de la solidaridad no patrocina, sin más y por sí misma, un sacrificio de naturaleza colectiva que - explicado de manera laxa, cuando no demagógica, y ayuno de un título convincente de habilitación- llegue a privar de derechos válidamente adquiridos y atentar contra los intereses legítimos de quienes tienen derecho a las prestaciones que el legislador ordinario reduce o suprime a través de una doble irregularidad. Una, la de conectar el fundamento de ese arbitrio con la novedad del art. 47 LGSS, cuyos vicios se han puesto de relieve. Otra, la de efectuarlo - te- 
naz y sistemáticamente- por medio del procedimiento que, previsto en el art. 134.3 a 5 CE para la elaboración y aprobación de los Presupuestos Generales del Estado, ha impedido que, hasta el momento, el Parlamento haya efectuado el examen y conclusiones que, como definidor de las líneas estructurales de la política económica, le competen. Frente a la fragilidad jurídica de esta situación y de otras que se le asemejan, se alza la enérgica advertencia con que el art. 136 II VCTR alude a la diversidad de las prácticas nacionales y da a entender que, mientras unas de ellas se producen y se desenvuelven conforme al signo del progreso social, otras, como la que aquí y ahora se critica, no se distinguen por esa excelencia.

Las objeciones de inconstitucionalidad se reiteraron cuando — con base en los títulos jurídicos que la misma justicia constitucional consideraba imprejuzgados y cuya utilización había sugerido- se suscitó un problema nuevo. A saber, el de la vulneración constitucional consistente en que la reiteración sistemática de la cláusula limitativa de la concurrencia y crecimiento de las pensiones públicas contributivas de jubilación y/o retiro - inserta en un cuerpo legal que, como las sucesivas Leyes de Presupuestos Generales del Estado, se tramitan abreviadamente y no admiten otras proposiciones o enmiendas que aquellas a las que, para aumentar o disminuir el gasto público, presta el Gobierno su conformidad (art. 134.6 CE) — sustraía, a la larga, a la plenitud del conocimiento legislativo una norma que el Parlamento - definidor, como se ha dicho, de las orientaciones centrales de la política económicatenía que emanar con las garantías de detenimiento y reflexión que los arts. 87 y sigs. CE asignan al proceso ordinario de elaboración de las leyes.

En vez de abordar el tema que su iniciativa había provocado, la justicia constitucional se limitó a admitir que el tenor de la nueva cuestión de inconstitucionalidad reconocía esos orígenes, pero no descendió al examen de la misma y, absteniéndose de analizar sus notables aspectos, concluyó en términos harto simplificadores. Sostuvo el parecer de que la fijación de los límites puestos en tela de juicio era coherente con la coyuntura política del momento, de suerte que - sin otras precisiones - cobraba, a la sazón, pleno sentido el que, según la previsión presupuestaria de cada anualidad, dichos límites se alterasen o desapareciesen. Se dio, sin más, por bueno el recurso a la tramitación utilizada - uno de cuyos más gruesos defectos se insinuaba en la invitación tácita a plantear la cuestión de inconstitucionalidad inédita hasta entonces- y se hizo una rotunda profesión de fe en la bondad de ese criterio, quedando sin dilucidar el fondo del problema que la propia justicia constitucional había incoado. 
A la hora de asentar las premisas dogmáticas del Derecho común europeo de la Seguridad Social, cae de su peso que — al margen de las desfiguraciones o falacias en que han podido incurrir las tentaciones arbitristas de los Estados miembros - la naturaleza de las cosas y la racionalidad políticolegislativa requieren que - mediante proposiciones generales, terminantes e inequívocas- se enuncien los principios relativos a la constitución de las relaciones protectoras de la Seguridad Social y se reafirmen las funciones de resarcimiento que sus prestaciones están llamadas a cumplir. Los postulados de orden público -indisponibles e inmodificables - que así se consolidan, no pueden exponerse a futuras deformaciones o posturas domésticas que se supeditan a las conveniencias de unas $\mathrm{u}$ otras legislaciones nacionales. La movilidad soberana de los Estados miembros queda condicionada, al fin, por la severidad uniformista que apareja la novísima revelación de los arts. 1361.2 y 137.3 mat. 1 VCTR. Sus postulados o premisas pasan a erigirse - como novedad llamativa y segura-en las verdades integrantes del contenido esencial o núcleo invulnerable de unos derechos fundamentales cuya condición de tales data de una postura de reconocimiento muy reciente, harto enfática y jurídicamente inobjetable. Dicho sea de paso, una vez más, no sin repercusión en la ordenación sistemática que, bajo la rúbrica De los derechos fundamentales y de las libertades públicas, encabeza la sec. 1. a , cap. 2. ${ }^{\circ}$, tít I CE. El cons. 4 Pr. VCTUE introduce la novedad -máximamente espectacular- de esa calificación y, para evitar cualesquiera objeciones sobre su irreprochable iniciativa, cuida de remitirse nada menos que al elenco de los derechos fundamentales de naturaleza social que figuran en la CSE y en la CCDSFT. Precisión, ésta, de impresionante magnitud y ausente, hasta entonces, del Pr. VATUE, que guardaba silencio sobre un pormenor tan importante. Sí que fue, en su momento, parte de la proclamación debilitada del Prot. PS, tras haber sido expulsada, por falta de la unanimidad exigida, de la parte dispositiva del cuerpo fundacional y haberse suscrito - excepción hecha del Reino Unido de la Gran Bretaña e Irlanda del Norte- por el resto mayoritario de los Estados miembros, que testimonialmente accedieron a compartir una fórmula de compromiso tan atípica como jurídicamente ineficaz.

No es dudoso que, conforme a la lúcida advertencia del art. 136 II VCTR, la llamada diversidad de las prácticas nacionales —en materia, entre otras, de Seguridad Social- puede deberse a las diferencias reguladoras y arbitrismos que generan medidas como la que - apartándose de los cánones universales del Derecho de la Seguridad Social que, según el art. 137.3 mat. 1 VCTR, han de fijarse a través de las futuras Directivas del Consejo - se critica respecto a la tasa del crecimiento y 
concurrencia de las pensiones públicas contributivas de jubilación y/o retiro.

\section{Reconsideración del problema a la luz de la naturaleza de derecho fundamental que el ordenamiento jurídico comunitario confiere al derecho a la Seguridad Social}

Las denuncias de inconstitucionalidad de esa medida corrieron la más infortunada de las suertes posibles. Inicialmente, porque la justicia constitucional desestimó los numerosos argumentos que, para combatir aquélla, acumularon los alegatos de inconstitucionalidad a que se dio respuesta. Más tarde, porque la misma justicia constitucional entendió resuelto, sin dedicarle el prometido análisis, el problema imprejuzgado y remanente que había incitado a promover y examinar. La actual elevación del derecho a la Seguridad Social a la categoría de derecho fundamental comunitario, obliga a reconsiderar el problema en términos acordes con dicha novedad.

El aspecto que se trae a capítulo concierne a la incompatibilidad de la medida criticada con los principios centrales del Derecho común europeo de la Seguridad Social, que, para responder a las exigencias políticolegislativas de los recientes derechos fundamentales, han de ajustarse a lo prescrito en los arts. 136 I y II, y 137.3 mat. 1 VCTR. La acción protectora de la Seguridad Social no admite, así las cosas, divergencias básicas de regulación ni excepciones o singularidades sorprendentes que - afectando, como en el caso contemplado sucede, al contenido esencial de derechos conquistados por el Estado Social de Derecho y ascendidos al máximo nivel— provoquen desigualdades privadas de una justificación estructural objetiva y razonable, ligadas a episodios de mera coyuntura, desprovistas de fundamentos técnicamente valederos y, en suma, reñidas con las normas de orden público, textual o virtual, que constituyen el nuevo basamento del Derecho Social europeo.

Uno de esos principios centrales —que, en el plano del ordenamiento social comunitario, reitera el rasgo de suficiencia y adecuación cuantitativa de las pensiones públicas contributivas de jubilación y/o retiro que proclaman los arts. 41 y $50 \mathrm{CE}$ - significa que la función indemnizatoria de las mismas - correspondiente a un razonable amparo del daño resarcible - debe tener en cuenta, a fin de aproximarse equitativamente a su cuantía, la magnitud del perjuicio que ocasiona la salida de la población activa y la pérdida de rentas de trabajo que, en lo sucesivo, dejan de obtenerse. Tal suficiencia no es la cobertura de los 
mínimos que lindan con el umbral de la pobreza, ni su objetivo se reduce a paliar las consecuencias del salto que provoca la inmersión en ese abismo.

El derecho a dichas prestaciones presupone la satisfacción de un interés legítimo cuya clave no estriba - pues el art. 65.1 Co. 102 OIT ya cuida de aclararlo- en el deseo o avidez de evitar una lastimosa indigencia, sino en el afán de conservar unos medios de vida que, aún sin alcanzar las percepciones anteriores a la adquisición del derecho a la pensión, se les acercan razonablemente y no se alejan de ellas en la medida reveladora de una lesión extraordinaria o enorme. Ningún sano criterio de solidaridad —entendido al modo de sacrificio razonable y no como arbitrio que, sin justificación bastante, deteriora el contenido esencial o núcleo invulnerable de los nuevos derechos fundamentales de naturaleza social- permite sustentar una interpretación en que ese alegato contuso y difuso interviene al margen del mandato o la prohibición explícita de la norma jurídica que hace falta para desencadenar tan conmovedores efectos.

Es consecuente que - dado lo insólito de la diversidad de la práctica nacional que la medida censurada ha introducido- deba el Consejo dar cumplimiento a lo dispuesto en el art. 136.3 mat. 1 y 4 VCTR. Lo cual exige - como conviene a la dificultad y envergadura de esa tarea constructiva- adoptar, por unanimidad, las normas rectoras que contengan el acervo de los principios generales garantizados por el constituyente europeo. Se trata de reglas cuya uniformidad - inherente a la naturaleza de las cosas e integrante del acervo cultural y social del Estado de Bienestar - ha de prevalecer sobre las acciones políticolegislativas de los Estados miembros en los aspectos capitales que atañen al régimen de adquisición y extensión económica de los derechos subjetivos a la acción protectora de la Seguridad Social. El principio ontológico de no contradicción - expresivo de que una cosa no puede ser y dejar de ser al mismo tiempo-proscribe que la suficiencia y adecuación de las pensiones públicas contributivas de jubilación y/o retiro constituyan un concepto equívoco que, en unos de los Estados miembros de la UE, sirve para designar la proximidad compensatoria de la cifra de esas prestaciones con relación a las rentas de trabajo que sus beneficiarios dejan de obtener cuando cesan en su actividad profesional, mientras que, en otros, no pasa de indicar la utilidad -ínfima y mínima- que sitúa en el umbral de acceso al mundo de la marginación social y la pobreza.

El derecho a las prestaciones económicas de la Seguridad Social se adquiere previo el cumplimiento de unos requisitos que incluyen la obligación legal de cotizar, inherente al carácter contributivo de las mismas. 
La importancia de la cotización - que representa un esfuerzo de contribución en el curso de la vida activa - es doble, pues, de una parte, condiciona la adquisición del derecho y, de otra, influye en la determinación de su extensión económica. Cierto que la aportación derivada del pago de esta obligación cumple un objetivo de solidaridad que flexibiliza satisfactoriamente la financiación del sistema y evita su quebranto, pero, en lo tocante a la formación de las relaciones protectoras, el ordenamiento jurídico tiene presente el cumplimiento del deber de cotizar para estimar la duración o continuidad del sacrificio — circunstancia de la que depende el reconocimiento del derecho a la prestación-y, no menos, para asignarle una cuantía dineraria suficiente y adecuada, es decir, sensiblemente próxima y nunca aparatosamente inferior a las rentas de trabajo sustituidas por la percepción del beneficio social.

Armonizando esta perspectiva con las reflexiones anteriores, los principios generales del Derecho Social comunitario - que atribuye naturaleza fundamental a los derechos de la Seguridad Social- implicarían, amén de otros, los enunciados que siguen:

1) Todo eventual beneficiario de una pensión pública contributiva de jubilación y/o retiro tiene derecho a que la continuidad de su contribución económica a la financiación del sistema - expresada en las unidades de tiempo que la legislación establececonstituya un presupuesto o condición indispensable para que, mediante los oportunos actos de gestión, las Administraciones Públicas competentes reconozcan su derecho a obtener la prestación interesada.

2) Cualquiera de los beneficiarios tiene derecho a que el objeto de esas prestaciones periódicas consista en una suma de dinero cuya cuantía alcance el nivel propio de una protección suficiente $\mathrm{y}$ adecuada, y que, a dicho fin, se fije - aplicando la fórmula correspondiente- sobre bases de cotización que, reflejando el esfuerzo de contribución al cumplimiento de las cargas públicas, coincidan con los emolumentos recientemente obtenidos por el trabajador que abandona la población activa.

3) Las prestaciones así calculadas satisfacen el contenido esencial o núcleo invulnerable del derecho fundamental a la Seguridad Social, que legitima su reconocimiento, y no pueden sufrir disminuciones que, so pretextos arbitristas o razones de conveniencia económica, las despojen de los rasgos de suficiencia y adecuación que les son inherentes.

4) La suficiencia y adecuación de los expresados beneficios sociales consisten en la capacidad económica de resarcir, efectiva y 
no sólo simbólicamente, el perjuicio causado por la pérdida de las rentas de trabajo, y proscriben cualquier reducción de su cuantía que degrade aparatosamente el resultado de las operaciones de cálculo.

5) Los derechos nacidos del reconocimiento de las pensiones públicas contributivas de jubilación y/o retiro que son entre sí compatibles, deben adquirir y conservar la extensión económica que deriva de las consideraciones anteriores, sin sufrir merma ni supresión alguna al ingresar en el patrimonio del titular común que reúne los requisitos exigidos para su atribución y disfrute.

\section{Conclusiones consecuentes con la actitud crítica que cabe sostener}

Es necesario que - a través de las correspondientes Directivas y con independencia de otros contenidos adicionales o complementarios- el Consejo ejercite, a propuesta de la Comisión y previa consulta al Parlamento Europeo, al Comité Económico y Social y al Comité de las Regiones, la competencia que el art. 137.3 mat. 1 VCTR le reserva para formular los principios de que forman parte las proposiciones que acaban de enunciarse. Tal es el sentido de la novedosa atribución que, por primera vez, sintoniza con la ambición y la esperanza de una Europa social comprometida con las aspiraciones de bienestar y de progreso que, tiempo atrás, puso de relieve el art. $12 \mathrm{CSE}$, al que el constituyente comunitario se remite de modo comprometido y vinculante.

No estaría de más que, por obra de una reflexión similar a la que anima estas consideraciones y al margen de simplismos economicistas, el art. 47 LGSS dejase de asignar a la Ley de Presupuestos Generales del Estado el papel - estructuralmente fuera de lugar- de fijar, sistemática e inexorablemente, límites anuales a la concurrencia y crecimiento de las pensiones públicas contributivas de jubilación y/o retiro, y redujese la hipótesis a la de las situaciones excepcionales que lo justifiquen convincentemente. No menos obligado sería que el legislador presupuestario — con la vista puesta en las admoniciones de los arts. 136 I y II, y 137.3 mat. I VCTR-tomase buena cuenta y razón de la singularidad representada por la elevación de los derechos sociales a la categoría de derechos fundamentales en el ámbito europeo, y reaccionase de acuerdo con el dato de que los mismos pasan a ser también derechos fundamentales en el ordenamiento jurídico español, pues el principio de primacía del Derecho comunitario no admite que un Estado miembro adjudique a sus derechos constitucionales calidad y consideración inferiores a las que, como en el 
caso que se trae a capítulo, les defiere el ordenamiento jurídico de la Unión Europea.

Las pensiones públicas contributivas de jubilación y/o retiro se erigen en el objeto de una relación protectora conexa con el reconocimiento del derecho a la Seguridad Social como derecho fundamental. Ni siquiera es dable apelar a la reserva de ley orgánica - constante en el art. 53.2 CE- para regular esos aspectos, pues el art. 136.3 mat. 1 y 4 VCTR impone una reserva de Directivas del Consejo que, absteniéndose de cuantas iniciativas atenten contra esta grave y severa restricción, los Estados miembros deben acatar sin condiciones. Nadie que comulgue y se sienta poseído del espíritu crítico, tendrá la peregrina ocurrencia de opinar, en defensa de una postura insostenible, que unos son los derechos fundamentales de condición comunitaria y otros los reconocidos por cada uno de los constituyentes nacionales. Este oficio de prestidigitación - poco sensato - asignaría al adjetivo fundamental una equivocidad vedada por el principio ontológico de no contradicción y, sobre todo, por la voluntad del constituyente europeo, que intencionalmente se adueña de un concepto que el pensamiento yusnaturalista del siglo XVII había inventado para augurar la suerte del moderno Derecho Constitucional.

El derecho a la Seguridad Social ha sido promovido a la categoría de derecho fundamental — con todas las connotaciones que esta calificación apareja - y, a causa de ello, queda fuera de duda la incompetencia del legislador ordinario - que debe abstenerse en lo sucesivo de utilizar un cauce semejante- para servirse del procedimiento del art. 134.3 a 5 CE, con el fin de mantener los límites anuales al crecimiento y concurrencia de las pensiones públicas contributivas de jubilación y/o retiro.

El Derecho fundamental a la efectiva tutela judicial no deja de intervenir en este aspecto. Las pretensiones dirigidas a invocar la protección del nuevo derecho fundamental a la Seguridad Social han de inspirarse únicamente en el imperio de la ley, como subraya el art. 117.1 CE, y la satisfacción de sus intereses legítimos no puede depender de acuerdos políticos que dan la impresión de estarse transigiendo, con benévola indulgencia, sobre bienes y valores que el ordenamiento jurídico declara indisponibles. La generalidad e indivisibilidad con que las Directivas del Consejo deben disciplinar ese aspecto del Derecho Social comunitario, desautorizan las prácticas nacionales viciadas y obligan a reconstituir, por unanimidad, los principios básicos correspondientes. No puede perpetuarse la impresión de que, en lugar de asumir y ejercitar con energía la condición de titular de sus derechos, el ciudadano - que, hace tiempo, dejó de ser súbdito- comulga con pre- 
juicios y conminaciones que, quiérase o no, le sumen en las reacciones y vivencias del síndrome de Estocolmo.

También se suscitan las cuestiones notables que se refieren a la intervención de los jueces ordinarios en el tratamiento del problema que origina la tasa de esas prestaciones públicas. No está de más reparar en alguna de ellas.

Los perceptores de las pensiones públicas contributivas de jubilación y/o retiro castigados por semejantes límites o privados de su percepción, a causa de la concurrencia de otro beneficio social compatible, tienen acción para exigir, ante los órganos del orden social de la jurisdicción, el pago íntegro de unas prestaciones a las que ya no afectan dichas restricciones. Sucede así, porque las Leyes de Presupuestos Generales del Estado no pueden regular de futuro aspectos relativos al contenido esencial o núcleo invulnerable del nuevo derecho fundamental a la Seguridad Social, que el art. 137.3 mat. 1 y 4 VCTR somete a la reserva de las normas de Derecho derivado consistentes en las Directivas que deben emanar del Consejo. De ahí, que, como se ha dicho, ni aun la reserva de ley orgánica baste para ocuparse de esa regulación con arreglo a Derecho.

Cabe asimismo preguntarse si, con motivo de dichas pretensiones, procede plantear, al amparo del art. $234 a V C T R$, una cuestión prejudicial que tenga por objeto obtener la respuesta de la jurisdicción comunitaria a la siguiente duda. ¿Deben los legisladores ordinarios de los Estados miembros —en vista de la reserva de Directiva que establece el art. 137.3 mat. 1 y 4 VCTR-abstenerse de adoptar —en el ámbito de la Seguridad Social que, según esa reserva, requiere decisiones tomadas por unanimidad-criterios nacionales o particularistas acerca de los aspectos estructurales o condiciones básicas que atañen al concepto inequívoco de suficiencia y adecuación de las prestaciones sociales, a la obligada fijación de su cuantía en dependencia de las bases de cotización, a la reducción aparatosa o desproporcionada del resultado del cálculo que así debe efectuarse, al influjo de las motivaciones económicas en la degradación de dichos beneficios y a la privación, sin indemnización alguna, de derechos legítimamente adquiridos por sus perceptores?

El derecho fundamental - que garantiza el art. $20.1 d \mathrm{CE}$ - a obtener y comunicar información veraz por cualquier medio, obliga a poner en conocimiento de quienes tienen la condición de interesados, su cualidad de titulares del derecho también fundamental - de estirpe e innovación comunitaria- a la acción protectora de la Seguridad Social. Su inalienabilidad y fortaleza exigen que — con la dificultad e imaginación que ello apareja- las soluciones económicas se piensen 
concienzudamente y se construyan en pro de su efectividad, y no se utilicen ni pretexten para erosionar su contenido esencial o núcleo invulnerable. Tanto en el aspecto examinado como en otros que pertenecen a la naturaleza y estructura del derecho fundamental así reconocido, los Estados miembros han de estar —diríase que religiosamente-al futuro Derecho común que, a propuesta de la Comisión y tras las preceptivas consultas, elabore el Consejo. Ningún derecho fundamental debe seguir expuesto al azar de las conveniencias domésticas o de los eventuales consensos de fuerzas políticas que no pueden sustituir la competencia de los órganos comunitarios ni contrariar las normas jurídicas que, en este caso, van a producirse, por unanimidad, en el ámbito de la Seguridad Social.

No huelga insistir sobre lo decisivo del papel que - lo mismo en el tema analizado que en otros muchos afectados por el laxismo del discurso político - desempeña la acción de los jueces ordinarios nacionales, jueces, en definitiva, del ámbito comunitario. Comprometidos - todos ellos- en la tarea de poner a punto el sector del Derecho objetivo que, fuera de arbitrismos y desorientaciones, reclama la contribución rigurosa del saber jurídico para proteger los nuevos derechos fundamentales emergentes y reconocidos en el espacio social europeo. 